\title{
Experimental Research on the Distribution of Chloride Ion Migration in Concrete Cover during Electrochemical Chloride Extraction Treatment
}

\author{
Jianghong Mao ${ }^{1}$, Kaiqi $\mathrm{Yu}^{1}$, Yidong $\mathrm{Xu}^{1, *}$, Xixi Wu ${ }^{2}$, Weiliang $\mathrm{Jin}^{1,2}$, Chen $\mathrm{Xu}^{2}$, Chonggen Pan ${ }^{1}$ \\ ${ }^{1}$ Ningbo institute of Technology, Zhejiang University, Ningbo 315100, China; \\ ${ }^{2}$ Institute of Structural Engineering, Zhejiang University, Hangzhou 310058, China \\ *E-mail: $\underline{x y d @ n i t . z j u . e d u . c n ~}$
}

doi: $10.20964 / 110462$

Received: 14 February 2016 / Accepted: 18 March 2016 / Published: 1 April 2016

\begin{abstract}
Electrochemical chloride extraction (ECE) technology can effectively remove chloride ions inside concrete cover and can improve the durability of reinforced concrete (RC) structures. The distribution of chloride ion migration during ECE treatment should be studied further. This paper focused on two research topics. The first topic was how chloride ions became distributed from the electro migration over time, especially during short term ECE treatments. The second topic was how the chloride ions distributed along the depth of the concrete cover. A special ECE treatment device was designed to establish electric field of chloride removal in order to obtain desirable effects. It was found that the most efficient period of treatment occurred in the first few days. Thus, indoor experiments could be useful for determining the end time of ECE treatment. Also, relatively higher amounts of chloride ions in surface concrete were observed, and therefore, the long-term durability of concrete after ECE treatment should be examined.
\end{abstract}

Keywords: reinforced concrete structures; concrete durability; electrochemical chloride extraction; spatial characteristics

\section{FULL TEXT}

(C) 2016 The Authors. Published by ESG (www.electrochemsci.org). This article is an open access article distributed under the terms and conditions of the Creative Commons Attribution license (http://creativecommons.org/licenses/by/4.0/). 